\title{
ANALYZE THE EFFECT OF TIME DELAY ON THE STABILITY OF HYBRID ACTIVE POWER FILTER
}

\author{
CHAU MINH THUYEN \\ Faculty of Electrical Engineering \& Technology, Industrial University of Ho Chi Minh City; \\ chauminhthuyen@iuh.edu.vn
}

\begin{abstract}
Hybrid Active Power Filter (HAPF) has highly effective in improving the power quality of power system. In this paper, a stable analysis of HAPF considering the time delay was made. The mathematical model of HAPF with time delay has been established. Based on that, the stable domain of the HAPF parameters was determined based on the Routh's stability standard. Simulation results based on Matlab software have shown that: time delay has a marked impact on the stability of the HAPF system. This research has practical significance in the design and control of HAPF in real system.
\end{abstract}

Keywords. Passive power filter, hybrid active power filter, stability analysis, time delay.

\section{INTRODUCTION}

Nowadays, the power electronic devices are very popular, such as motor drives, converters in renewable, electric arc furnace, uninterruptible Power Supply, etc. All of these devices are nonlinear loads. The nonlinear loads are the sources of the harmonic distortion; it affect directly to grid and reduces power quality of the power system. There are many ways to solve this problem such as using a passive power filter (PPF), active power filter (APF) and hybrid active power filter (HAPF). The passive power filters are simple, low cost, ability to compensate reactive power and harmonic filter [1-3]. However, they are many disadvantages such as resonance with supply system, no flexibility in harmonic filtering also reactive power compensation, instability in power system.

A new harmonic filter method based on power electronic devices is an active power filter (APF). The APF is connected parallel with nonlinear loads and harmonic elimination more flexibility than PPF. However, APF is limited by high cost, small capacity, less life of power electronic devices and difficult connection with high voltage network [4-5]. To solve these problems, hybrid active power filter is studied. HAPF is a topology that is combined by passive power filter (PPF) and active power filter (APF). Hence the HAPF inherits the advantages of both passive power filter (PPF) and active power filter (APF). Hybrid active power filter (HAPF) flexibly eliminated harmonic, greatly reduced power rating of APF, avoided resonance with the supply system, connected with high voltage network [6-10]. Therefore, studying about the hybrid active power filter is a necessary role to contribute energy saving, especially save energy at business, office, school, factory, etc. Also improve power quality in power system.

Determination of the exact parameters of the hybrid active power filter will decide its performance. So far these parameters of hybrid active power filter are most determined based on experience but not considering stable system. Moreover, researches [11-16] are not considering time delay. In HAPF system, from harmonic current signal of load to compensation of current into the grid must through many elements such as capacitors, coils, transformer, output filter, voltage source inverter, controller, etc. All these elements created time delay at output. The time delay affected the efficiency and stability of HAPF. In this paper, the mathematical model of HAPF is established with considering time delay of system. Since then, an analysis of the stability of the HAPF system is established to find a stable domain for parameters of HAPF. This has practical significance for improving work efficiency of HAPF in the real system conditions.

\section{TOPOLOGY AND OPERTING PRINCIPLE OF HAPF}

The topology of HAPF is shown in Figure 1.

In Figure $1, \mathrm{U}_{\mathrm{s}}$ and $\mathrm{Z}_{\mathrm{s}}$ are supply voltage and equivalent impedance of the grid. $\mathrm{C}_{\mathrm{F}}, \mathrm{C}_{1}, \mathrm{~L}_{1}, \mathrm{C}_{\mathrm{p}}, \mathrm{L}_{\mathrm{p}}, \mathrm{L}_{0}, \mathrm{C}_{0}$ are the injection capacitor, fundamental resonance capacitor, fundamental resonance inductor, the capacitor and inductor of the passive power filters, the capacitor and inductor of the output filter. A branch with $\mathrm{C}_{\mathrm{F}}$ $\mathrm{C}_{1}-\mathrm{L}_{1}$ is injected to reduce capacity of APF. $\mathrm{C}_{1}$ and $\mathrm{L}_{1}$ resonate at the fundamental frequency and connect in series with additional branch $\mathrm{C}_{\mathrm{F}}$. Nonlinear loads are considered as sources of harmonics. Most high order harmonics will be reduced by the passive filter PPF. In this paper, the passive filters eliminate the $11^{\text {th }}$ 
and $13^{\text {th }}$ order harmonics. Moreover, the APF also rejects some remaining low order harmonics. Thus the capacity of PPF is reduced significantly.

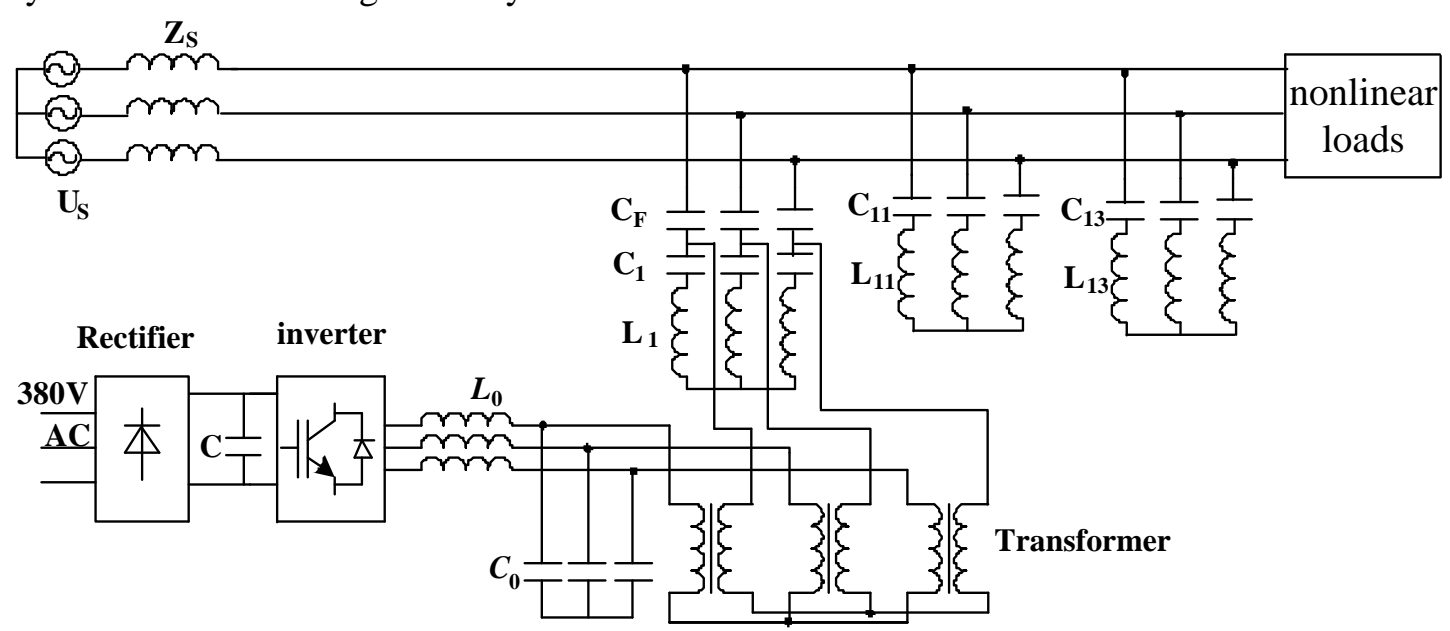

Figure 1: Topology of HAPF.

The single phase equivalent circuit of HAPF is shown in Figure 2.

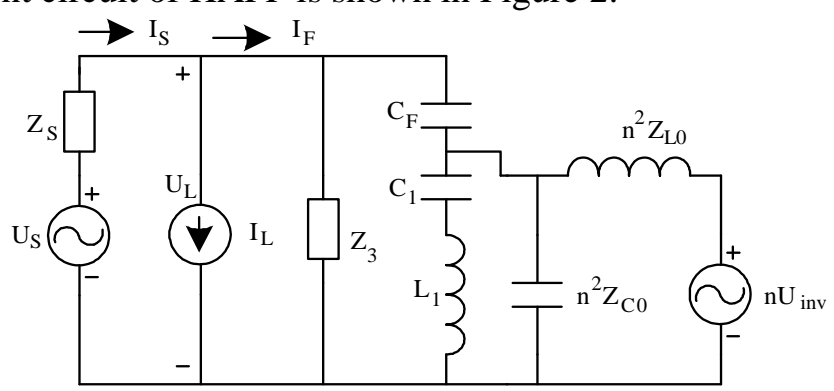

Figure 2: Single phase equivalent circuit of HAPF.

Where:

The impedance of resonance at fundamental frequency branch $Z_{C_{1} L_{1}}=Z_{C 1}+Z_{L 1}$

The impedance of additional branch $Z_{2}=Z_{C F}$

The impedance of the PPFs is $\mathrm{Z}_{3}$. Where $\mathrm{R}_{11}-\mathrm{C}_{11}-\mathrm{L}_{11}$ branch and $\mathrm{R}_{13}-\mathrm{C}_{13}-\mathrm{L}_{13}$ branch are inner resistance of inductor, capacitor and inductor that tuned at the $11^{\text {th }}$ and $13^{\text {th }}$ harmonics. In each passive filter branch, the impedance is

$$
\left\{\begin{array}{l}
Z_{11}=Z_{R_{11}}+Z_{C_{11}}+Z_{L_{11}} \\
Z_{13}=Z_{R_{13}}+Z_{C_{13}}+Z_{L_{13}}
\end{array}\right.
$$

The single phase equivalent circuit with the effect of harmonic source is shown in Figure 3 with output current of APF is $i_{a p f}$.

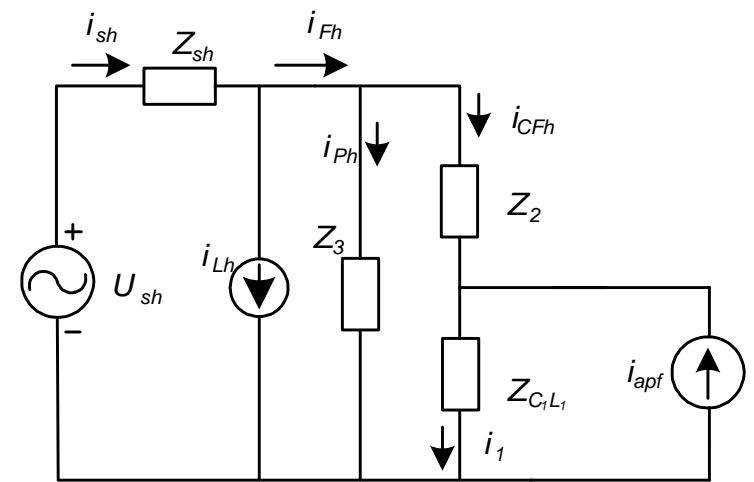

Figure 3: Single phase equivalent circuit with the effect of harmonic source.

According to Figure 3, if we control to achieve the purpose $I_{F h}=-I_{L h}$ then we will obtain $I_{\mathrm{sh}}=0$. 
With control strategy $I_{a p f}=K I_{L h}$ is output current of APF. According to Figure 3, equations are established:

From (1), $I_{s h}$ is calculated as

$$
\left\{\begin{array}{l}
I_{s h}=I_{L h}+I_{F h} \\
I_{1}=I_{a p f}+I_{C F h} \\
I_{F h}=I_{P h}+I_{C F h} \\
I_{s h} Z_{s h}+I_{P h} Z_{3}=U_{s h} \\
I_{C F h} Z_{2}+I_{1} Z_{C 1 L 1}=I_{P h} Z_{3}
\end{array}\right.
$$

$$
I_{s h}=\frac{\left(Z_{2}+Z_{C 1 L 1}-K Z_{C 1 L 1}\right) Z_{3} I_{L h}}{\left(Z_{2}+Z_{C 1 L 1}\right)\left(Z_{3}+Z_{s h}\right)+Z_{3} Z_{s h}}
$$

The equation (2) showed that if $\mathrm{K}$ is large enough, the harmonic current source components will gain a value of zero. $\mathrm{K}$ is the coefficient control and depends on many elements such as control strategy, parameters, topology...

If only considering the response of the voltage source inverter, $U_{s}=0, i_{L}=0$. The single phase equivalent circuit is shown in Figure 4.

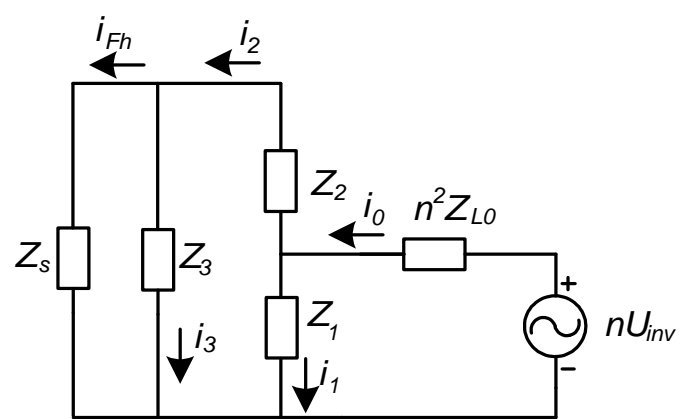

Where:

Figure 4: Single phase equivalent circuit when only considering VSI.

$$
\left\{\begin{array}{l}
Z_{s}=R_{s}+L_{s} s \\
Z_{1}=Z_{L 1} C_{1} / / n^{2} Z_{C 0}=\left(R_{1}+L_{1} s+\frac{1}{C_{1} s}\right) / / \frac{n^{2}}{C_{0} s}=\frac{\frac{n^{2}}{C_{0} s}\left(R_{1}+L_{1} s+\frac{1}{C_{1} s}\right)}{\frac{n^{2}}{C_{0} s}+R_{1}+L_{1} s+\frac{1}{C_{1} s}} \\
Z_{2}=\frac{1}{C_{F} s} \\
Z_{L 0}=R_{0}+L_{0} s
\end{array}\right.
$$

According Figure 4, equations are established:

$$
\left\{\begin{array}{l}
I_{2}=I_{F h}+I_{3} \\
I_{L 0}=I_{2}+I_{1} \\
I_{F h} Z_{s}=I_{3} Z_{3} \\
I_{1} Z_{1}+I_{L 0} n^{2} Z_{L 0}=n U_{i n v} \\
I_{F h} Z_{s}+I_{2} Z_{2}+I_{L 0} n^{2} Z_{L 0}=n U_{i n v}
\end{array}\right.
$$

With $\mathrm{I}_{\mathrm{Fh}}$ is compensation harmonic current that is controlled by VSI, VSI as a controlled voltage source. From (4), $\mathrm{I}_{\mathrm{Fh}}$ can be calculated as (5)

$$
I_{F h}=\frac{n U_{i n v} \cdot Z_{1} \cdot Z_{3}}{n^{2} Z_{L 0}\left[Z_{3}\left(Z_{1}+Z_{2}\right)+Z_{s}\left(Z_{1}+Z_{2}+Z_{3}\right)\right]+Z_{1}\left(Z_{2} Z_{s}+Z_{2} Z_{3}+Z_{3} Z_{s}\right)}
$$


The transfer function of compensation harmonic current $\mathrm{I}_{F h}$ along the controlled voltage source $U_{i n v}$ is $G_{\text {out }}(s)$

$$
G_{\text {out }}(s)=\frac{i_{F h}}{U_{\text {inv }}}=\frac{n \cdot Z_{1} \cdot Z_{3}}{n^{2} Z_{L 0}\left[Z_{3}\left(Z_{1}+Z_{2}\right)+Z_{s}\left(Z_{1}+Z_{2}+Z_{3}\right)\right]+Z_{1}\left(Z_{2} Z_{s}+Z_{2} Z_{3}+Z_{3} Z_{s}\right)}
$$

There are two control strategies for $U_{i n v}$ based on load harmonic current detection and source harmonic current detection. In this paper, the control strategy is based on load harmonic current detection. Here the load harmonic current detection is calculated based on $\mathrm{i}_{\mathrm{p}} \mathrm{i}_{\mathrm{q}}$ harmonic detection method ${ }^{[6],[10]}$.

From the above analysis, we can see that the HAPF system has not time delay. With time delay is constituted by processes of the HAPF system, control block diagram of HAPF is shown in Figure 5. Where $\mathrm{G}_{\mathrm{c}}(\mathrm{s})$ and $\mathrm{G}_{\text {inv }}(\mathrm{s})$ are transfer functions of the conventional PI controller and the VSI.

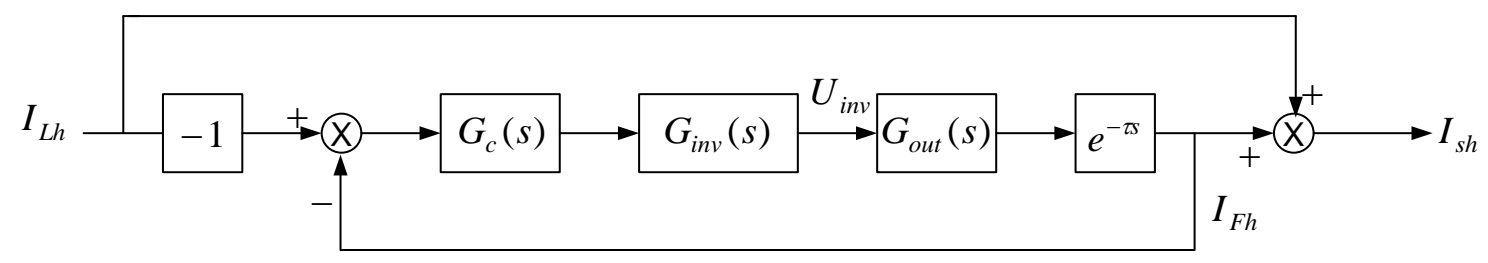

Figure 5: Control block diagram of HAPF.

The transfer function of the conventional PI controller:

$$
G_{c}(s)=K_{p}\left(1+\frac{1}{T_{i} s}\right)
$$

Where $\mathrm{K}_{\mathrm{p}}$ is the proportional gain constant and $\mathrm{T}_{\mathrm{i}}$ is the integral time.

The transfer function of VSI is expressed:

$$
G_{i n v}(s)=\frac{K_{i n v}}{T_{i n v} s+1}
$$

Where $\mathrm{K}_{\text {inv }}$ is amplification factor of the VSI and $\mathrm{T}_{\text {inv }}$ is time delay of the VSI.

The time delay of the entire system of HAPF is $\tau$ and can be represented as $\mathrm{e}^{-\tau s}$ function. To facilitate the analysis, may be simplified as follow

$$
e^{-\tau s}=\frac{1}{e^{\tau s}} \sim \frac{1}{1+\tau s+\frac{(\tau s)^{2}}{2 !}}
$$

According to control block diagram of HAPF in Figure 5, the control transfer function with load current input signal $\mathrm{I}_{\mathrm{Lh}}$ and source current output signal $\mathrm{I}_{\mathrm{sh}}$ of HAPF system with time delay $\mathrm{e}^{-\tau \mathrm{s}}$ is calculated

$$
G(s)=\frac{I_{s h}}{I_{L h}}=\frac{1}{1+G_{c}(s) \cdot G_{i n v}(s) \cdot G_{\text {out }}(s) \cdot e^{-\tau s}}
$$

\section{STABILITY ANALYSIS OF HAPF IN CONSIDERING TIME DELAY}

There are many criteria used to assess the stability of a system of such: Routh criterion, Hurwitz criterion, the root locus, Bode plots, Nyquist plots, etc. In this paper, Routh criterion used stability analysis of HAPF. To consider the stability of the system according to Routh criterion, first establishing Routh table follows rules. The elements in row $i$ column $j$ of Routh table $(i \geq 3)$ are calculated:

$$
c_{i j}=c_{i-2, j+1}-\alpha_{i} \cdot c_{i-1, j+1}
$$

Where $\alpha=\frac{c_{i-2,1}}{c_{i-1,1}}$

From (10), the characteristic equation of the control transfer function of HAPF system is determined

$$
D(s)=a_{0} s^{11}+a_{1} s^{10}+a_{2} s^{9}+a_{3} s^{8}+a_{4} s^{7}+a_{5} s^{6}+a_{6} s^{5}+a_{7} s^{4}+a_{8} s^{3}+a_{9} s^{2}+a_{10} s^{1}+a_{11} s^{0}
$$

Where the coefficients $a_{0} \ldots a_{11}$ are coefficients of the characteristic equation (12) with the $11^{\text {th }}$ degree, that is the highest degree of the equation. The coefficients are calculated: 
$a_{0}=T_{i} \tau^{2} A_{1} ; a_{1}=T_{i}\left(2 \tau A_{1}+\tau^{2} A_{2}\right) ; a_{2}=T_{i}\left(2 A_{1}+2 \tau A_{2}+\tau^{2} A_{3}\right) ; a_{3}=T_{i}\left(2 A_{2}+2 \tau A_{3}+\tau^{2} A_{4}\right) ;$

$a_{4}=T_{i}\left(2 A_{3}+2 \tau A_{4}+\tau^{2} A_{5}+2 n K_{c} C_{F} B_{1}\right) ; a_{5}=T_{i}\left(2 A_{4}+2 \tau A_{5}+\tau^{2} A_{6}+2 n K_{c} C_{F} B_{2}\right) ;$

$a_{6}=T_{i}\left(2 A_{5}+2 \tau A_{6}+\tau^{2} A_{7}+2 n K_{c} C_{F} B_{3}\right) ; a_{7}=T_{i}\left(2 A_{6}+2 \tau A_{7}+\tau^{2} A_{8}+2 n K_{c} C_{F} B_{4}\right) ;$

$a_{8}=T_{i}\left(2 A_{7}+2 \tau A_{8}+\tau^{2} A_{9}+2 n K_{c} C_{F} B_{5}\right) ; a_{9}=T_{i}\left(2 A_{8}+2 \tau A_{9}+\tau^{2}+2 n K_{c} C_{F} B_{6}\right) ;$

$a_{10}=2 T_{i}\left(A_{9}+\tau+\tau^{2}+n K_{c} C_{F} B_{7}\right) ; a_{11}=2 T_{i}\left(1+n K_{c} C_{F}\right)$

Where:

$K_{c}=K_{i n v} \times K_{p} ; \mathrm{n}$ is the transfer ratio of the transformer and the expressions from $\mathrm{A}_{1}$ to $\mathrm{A}_{9}$ and $\mathrm{B}_{1}$ to $\mathrm{B}_{7}$ are determined by the Appendix.

From the coefficients of the characteristic equation (12) can be established Routh table to survey of stability of HAPF system. To determine the HAPF is stable, then the all of elements at first column are positive. Thus the stable domain of parameters of the HAPF system is determined as (13)

$$
\left\{\begin{array}{l}
c_{11}>0 \\
c_{21}>0 \\
c_{31}>0 \\
c_{41}>0 \\
c_{51}>0 \\
c_{61}>0 \\
c_{71}>0 \\
c_{81}>0 \\
c_{91}>0 \\
c_{101}>0 \\
c_{111}>0 \\
c_{121}>0
\end{array}\right.
$$

Where the coefficients from $\mathrm{c}_{11}$ to $\mathrm{c}_{121}$ are calculated in Appendix

\section{SIMULATION RESULTS AND DISCUSSION}

To demonstrate the influence of time delay on the stability of the system HAPF, simulation results are implemented on a system HAPF $10 \mathrm{kV}-50 \mathrm{~Hz}$ with parameters as in [5] and are listed as in Table 1. Nonlinear loads contain order harmonics such as such as $5^{\text {th }}, 7^{\text {th }}, 11^{\text {th }}$ and $13^{\text {th }}$. The dc-side voltage is $600 \mathrm{~V}$.

Table 1: Parameters of system simulation.

\begin{tabular}{|l|c|c|c|}
\hline Parameters & $\mathrm{R}(\Omega)$ & $\mathrm{L}(\mathrm{mH})$ & $\mathrm{C}(\mu \mathrm{F})$ \\
\hline $11^{\text {th }}$ turned filter & 0.0157 & 1.77 & 49.75 \\
\hline $13^{\text {th }}$ turned filter & 0.086 & 1.37 & 44.76 \\
\hline Fundamental resonance circuit & 0.0168 & 14.75 & 690 \\
\hline Injection circuit & - & - & 29.65 \\
\hline Output filter & - & 0.2 & - \\
\hline
\end{tabular}

When $\tau=10^{-8} \mathrm{~s}, \mathrm{~T}_{\mathrm{inv}}=0.01 \mathrm{~ms}, \mathrm{~K}_{\mathrm{inv}}=1, \mathrm{~T}_{\mathrm{i}}=10^{-6} \mathrm{~s}, \mathrm{~K}_{\mathrm{c}}=100$ the elements in first column of Routh table $\mathrm{c}_{11}, \mathrm{c}_{21}$, $\mathrm{c}_{31}, \mathrm{c}_{41}, \mathrm{c}_{51}, \mathrm{c}_{61}, \mathrm{c}_{71}, \mathrm{c}_{81}, \mathrm{c}_{91}, \mathrm{c}_{101}, \mathrm{c}_{111}$ and $\mathrm{c}_{121}$ are determined in Table 2. All elements at first column are positive, that HAPF system is stable operation.

Now, we change time delay of the HAPF system: $\tau=0.0095 \mathrm{~s}, \mathrm{~T}_{\mathrm{inv}}=0.01 \mathrm{~ms}, \mathrm{~K}_{\mathrm{inv}}=1, \mathrm{~T}_{\mathrm{i}}=10^{-6} \mathrm{~s}, \mathrm{~K}_{\mathrm{c}}=100$. Calculate the parameters of the Routh table we can see that the elements $\mathrm{c}_{51}$ and $\mathrm{c}_{111}$ at first column Table 3 change sign. According to Routh criterion, the HAPF system with these parameters won't be stabilize when it operate.

To demonstrate the above analysis, the simulation results done in MATLAB software, the HAPF system with the parameters in the stable domain is shown in Figure 6. The HAPF system will be stabilize after the transitional period $0.01 \mathrm{~s}$. 
The grid current harmonic spectrum with the parameters in the stable domain is shown Figure 7. The total harmonic distortion THD of supply current in this case is 3.38\%, satisfaction of IEEE Std 1547TM and IEEE 519-2014 Standard [17-18].

Table 2: The elements of the Routh table with $\tau=10^{-8} \mathrm{~S}$

\begin{tabular}{|c|c|c|c|c|c|c|}
\hline $\mathbf{S}^{11}$ & $\begin{array}{c}c_{11}= \\
6.9612 \mathrm{E}-55\end{array}$ & $\begin{array}{c}c_{12}= \\
1.4061 \mathrm{E}-38\end{array}$ & $\begin{array}{c}c_{13}= \\
6.71 \mathrm{E}-28\end{array}$ & $\begin{array}{c}c_{14}= \\
2.88 \mathrm{E}-20\end{array}$ & $\begin{array}{c}c_{15}= \\
2.85 \mathrm{E}-13\end{array}$ & $\begin{array}{c}c_{16}= \\
1.63 \mathrm{E}-07\end{array}$ \\
\hline $\mathbf{S}^{10}$ & $\begin{array}{c}c_{21}= \\
1.40 \mathrm{E}-46\end{array}$ & $\begin{array}{c}c_{22}= \\
1.3941 \mathrm{E}-32\end{array}$ & $\begin{array}{c}c_{23}= \\
6.52 \mathrm{E}-22\end{array}$ & $\begin{array}{c}\mathrm{c}_{24}= \\
1.81 \mathrm{E}-14\end{array}$ & $\begin{array}{c}c_{25}= \\
1.22 \mathrm{E}-07\end{array}$ & $\begin{array}{c}c_{26}= \\
1.19 \mathrm{E}-02\end{array}$ \\
\hline $\mathbf{s}^{9}$ & $\begin{array}{c}c_{31}= \\
1.40 \mathrm{E}-38\end{array}$ & $\begin{array}{c}c_{32}= \\
6.68 \mathrm{E}-28\end{array}$ & $\begin{array}{c}c_{33}= \\
2.87 \mathrm{E}-20\end{array}$ & $\begin{array}{c}c_{34}= \\
2.84 \mathrm{E}-13\end{array}$ & $\begin{array}{c}c_{35}= \\
1.63 \mathrm{E}-07\end{array}$ & \\
\hline $\mathbf{s}^{8}$ & $\begin{array}{c}\mathrm{c}_{41}= \\
1.39 \mathrm{E}-32\end{array}$ & $\begin{array}{c}c_{42}= \\
6.52 \mathrm{E}-22\end{array}$ & $\begin{array}{c}\mathrm{c}_{43}= \\
1.81 \mathrm{E}-14\end{array}$ & $\begin{array}{c}\mathrm{c}_{44}= \\
1.22 \mathrm{E}-07\end{array}$ & $\begin{array}{c}\mathrm{c}_{45}= \\
1.19 \mathrm{E}-02\end{array}$ & \\
\hline $\mathbf{s}^{7}$ & $\begin{array}{c}\mathrm{c}_{51}= \\
1.32 \mathrm{E}-29 \\
\end{array}$ & $\begin{array}{c}c_{52}= \\
1.05 \mathrm{E}-20 \\
\end{array}$ & $\begin{array}{c}c_{53}= \\
1.61 \mathrm{E}-13\end{array}$ & $\begin{array}{c}c_{54}= \\
1.51 \mathrm{E}-07\end{array}$ & & \\
\hline$s^{6}$ & $\begin{array}{c}c_{61}= \\
6.41 \mathrm{E}-22\end{array}$ & $\begin{array}{c}\mathrm{c}_{62}= \\
1.79 \mathrm{E}-14\end{array}$ & $\begin{array}{c}\mathrm{c}_{63}= \\
1.22 \mathrm{E}-07\end{array}$ & $\begin{array}{c}\mathrm{c}_{64}= \\
1.19 \mathrm{E}-02\end{array}$ & & \\
\hline $\mathbf{s}^{5}$ & $\begin{array}{c}\mathrm{c}_{71}= \\
1.01 \mathrm{E}-20\end{array}$ & $\begin{array}{c}\mathrm{c}_{72}= \\
1.59 \mathrm{E}-13\end{array}$ & $\begin{array}{c}c_{73}= \\
1.51 \mathrm{E}-07\end{array}$ & & & \\
\hline $\mathbf{s}^{4}$ & $\begin{array}{c}\mathrm{c}_{81}= \\
7.87 \mathrm{E}-15\end{array}$ & $\begin{array}{c}\mathrm{c}_{82}= \\
1.13 \mathrm{E}-07\end{array}$ & $\begin{array}{c}\mathrm{c}_{83}= \\
1.19 \mathrm{E}-02\end{array}$ & & & \\
\hline $\mathbf{s}^{\mathbf{3}}$ & $\begin{array}{c}c_{91}= \\
1.38 \mathrm{E}-14\end{array}$ & $\begin{array}{c}c_{92}= \\
1.36 \mathrm{E}-07\end{array}$ & & & & \\
\hline $\mathbf{s}^{2}$ & $\begin{array}{c}c_{101}= \\
3.52 \mathrm{E}-08\end{array}$ & $\begin{array}{c}c_{102}= \\
1.19 \mathrm{E}-02\end{array}$ & & & & \\
\hline $\mathbf{s}^{1}$ & $\begin{array}{c}c_{111}= \\
1.31 \mathrm{E}-07\end{array}$ & & & & & \\
\hline $\mathbf{s}^{\mathbf{0}}$ & $\begin{array}{c}c_{121}= \\
1.19 \mathrm{E}-02\end{array}$ & & & & & \\
\hline
\end{tabular}

Table 3: The elements of the Routh table with $\tau=0.0095 \mathrm{~s}$.

\begin{tabular}{|c|c|c|c|c|c|c|}
\hline $\mathrm{s}^{11}$ & $\begin{array}{c}\mathrm{c}_{11}= \\
6.28252 \mathrm{E}-35\end{array}$ & $\begin{array}{c}\mathrm{c}_{12}= \\
2.4509 \mathrm{E}-27\end{array}$ & $\begin{array}{c}c_{13}= \\
2.75 \mathrm{E}-20\end{array}$ & $\begin{array}{c}c_{14}= \\
1.23 \mathrm{E}-13\end{array}$ & $\begin{array}{c}\mathrm{c}_{15}= \\
3.17 \mathrm{E}-08\end{array}$ & $\begin{array}{c}c_{16}= \\
2.12 \mathrm{E}-03\end{array}$ \\
\hline $\mathbf{s}^{10}$ & $\begin{array}{c}c_{21}= \\
1.62 \mathrm{E}-31\end{array}$ & $\begin{array}{c}\mathrm{c}_{22}= \\
3.0786 \mathrm{E}-24\end{array}$ & $\begin{array}{c}\mathrm{c}_{23}= \\
3.57 \mathrm{E}-17\end{array}$ & $\begin{array}{c}\mathrm{c}_{24}= \\
1.19 \mathrm{E}-10\end{array}$ & $\begin{array}{c}\mathrm{c}_{25}= \\
1.30 \mathrm{E}-05\end{array}$ & $\begin{array}{c}\mathrm{c}_{26}= \\
2.00 \mathrm{E}-01\end{array}$ \\
\hline $\mathbf{s}^{9}$ & $\begin{array}{c}c_{31}= \\
1.26 \mathrm{E}-27\end{array}$ & $\begin{array}{c}c_{32}= \\
1.37 \mathrm{E}-20\end{array}$ & $\begin{array}{c}c_{33}= \\
7.68 \mathrm{E}-14\end{array}$ & $\begin{array}{c}c_{34}= \\
2.66 \mathrm{E}-08\end{array}$ & $\begin{array}{c}c_{35}= \\
2.04 \mathrm{E}-03\end{array}$ & \\
\hline $\mathbf{s}^{8}$ & $\begin{array}{c}\mathrm{c}_{41}= \\
1.31 \mathrm{E}-24\end{array}$ & $\begin{array}{c}\mathrm{c}_{42}= \\
2.58 \mathrm{E}-17\end{array}$ & $\begin{array}{c}\mathrm{c}_{43}= \\
1.15 \mathrm{E}-10\end{array}$ & $\begin{array}{c}\mathrm{c}_{44}= \\
1.28 \mathrm{E}-05\end{array}$ & $\begin{array}{c}\mathrm{c}_{45}= \\
2.00 \mathrm{E}-01\end{array}$ & \\
\hline $\mathbf{s}^{7}$ & $\begin{array}{c}c_{51}= \\
-1.11 E-20\end{array}$ & $\begin{array}{c}c_{52}= \\
-3.38 \mathrm{E}-14\end{array}$ & $\begin{array}{c}c_{53}= \\
1.43 \mathrm{E}-08\end{array}$ & $\begin{array}{c}c_{54}= \\
1.85 \mathrm{E}-03\end{array}$ & & \\
\hline$s^{6}$ & $\begin{array}{c}\mathrm{c}_{61}= \\
2.18 \mathrm{E}-17\end{array}$ & $\begin{array}{c}c_{62}= \\
1.17 \mathrm{E}-10\end{array}$ & $\begin{array}{c}\mathrm{c}_{63}= \\
1.30 \mathrm{E}-05\end{array}$ & $\begin{array}{c}\mathrm{c}_{64}= \\
2.00 \mathrm{E}-01\end{array}$ & & \\
\hline $\mathbf{s}^{5}$ & $\begin{array}{c}c_{71}= \\
2.56 \mathrm{E}-14\end{array}$ & $\begin{array}{c}c_{72}= \\
2.09 \mathrm{E}-08\end{array}$ & $\begin{array}{c}\mathrm{c}_{73}= \\
1.95 \mathrm{E}-03\end{array}$ & & & \\
\hline $\mathbf{s}^{4}$ & $\begin{array}{c}\mathrm{c}_{81}= \\
9.91 \mathrm{E}-11\end{array}$ & $\begin{array}{c}\mathrm{c}_{82}= \\
1.13 \mathrm{E}-05\end{array}$ & $\begin{array}{c}\mathrm{c}_{83}= \\
2.00 \mathrm{E}-01\end{array}$ & & & \\
\hline $\mathbf{s}^{\mathbf{3}}$ & $\begin{array}{c}\mathrm{c}_{91}= \\
1.80 \mathrm{E}-08\end{array}$ & $\begin{array}{c}c_{92}= \\
1.90 \mathrm{E}-03\end{array}$ & & & & \\
\hline $\mathbf{s}^{2}$ & $\begin{array}{c}c_{101}= \\
9.06 \mathrm{E}-07\end{array}$ & $\begin{array}{c}c_{102}= \\
2.00 \mathrm{E}-01\end{array}$ & & & & \\
\hline $\mathbf{s}^{1}$ & $\begin{array}{c}c_{111}= \\
-2.08 E-03 \\
\end{array}$ & & & & & \\
\hline $\mathbf{s}^{\mathbf{0}}$ & $\begin{array}{c}c_{121}= \\
2.00 \mathrm{E}-01\end{array}$ & & & & & \\
\hline
\end{tabular}

Simulation results of the HAPF system with the parameter $\tau$ changed is shown Figure 8. These parameters of HAPF are set outside of stable domain with time delay $\tau=0.0095 \mathrm{~s}, \mathrm{~T}_{\mathrm{inv}}=0.01 \mathrm{~ms}, \mathrm{~K}_{\mathrm{inv}}=1, \mathrm{~T}_{\mathrm{i}}=0.1 \mathrm{~s}, \mathrm{~K}_{\mathrm{c}}$ 
$=100$. The HAPF system will be destabilized from $0.0095 \mathrm{~s}$ to $0.2 \mathrm{~s}$. The supply current increases to $1600 \mathrm{~A}$ and the current error is $1500 \mathrm{~A}$.

The supply current harmonic spectrum with the parameters outside of stable domain is shown Figure 9 . The total harmonic distortion THD of supply current in this case is $379.21 \%$. The individual harmonic components almost increase higher than in case the parameters of in the stable domain, not satisfying power quality standards in power system [17-18].
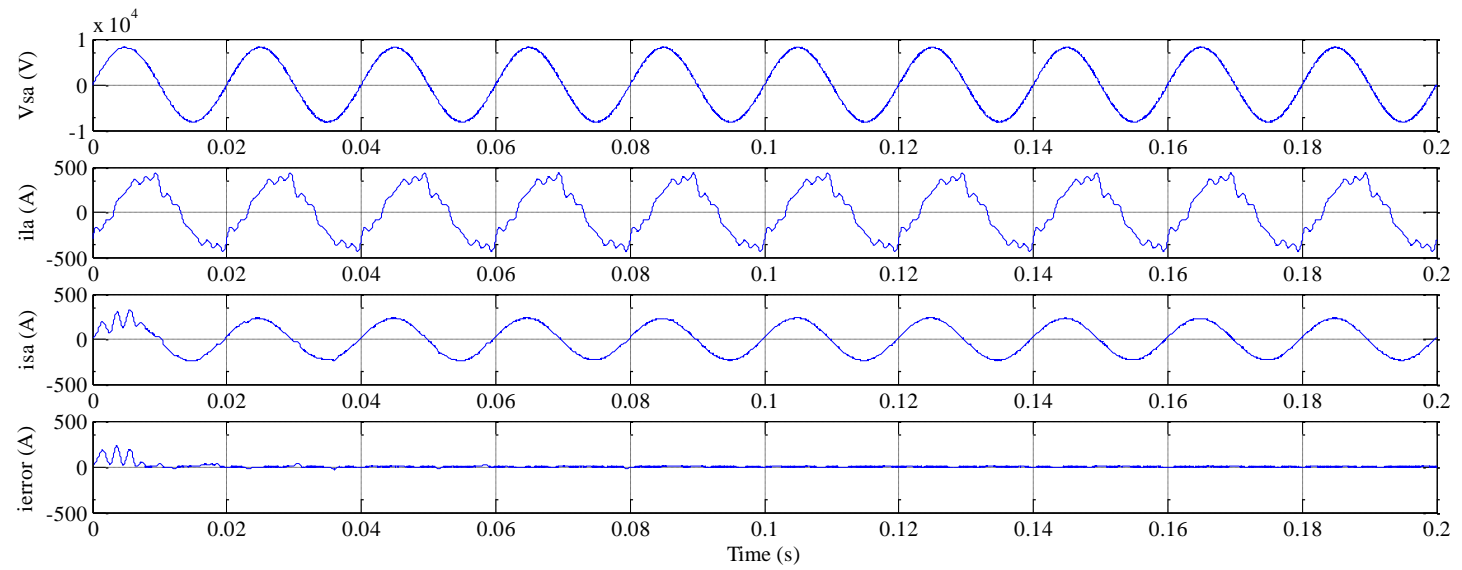

Figure 6: Response of HAPF with the parameters in the stable domain.

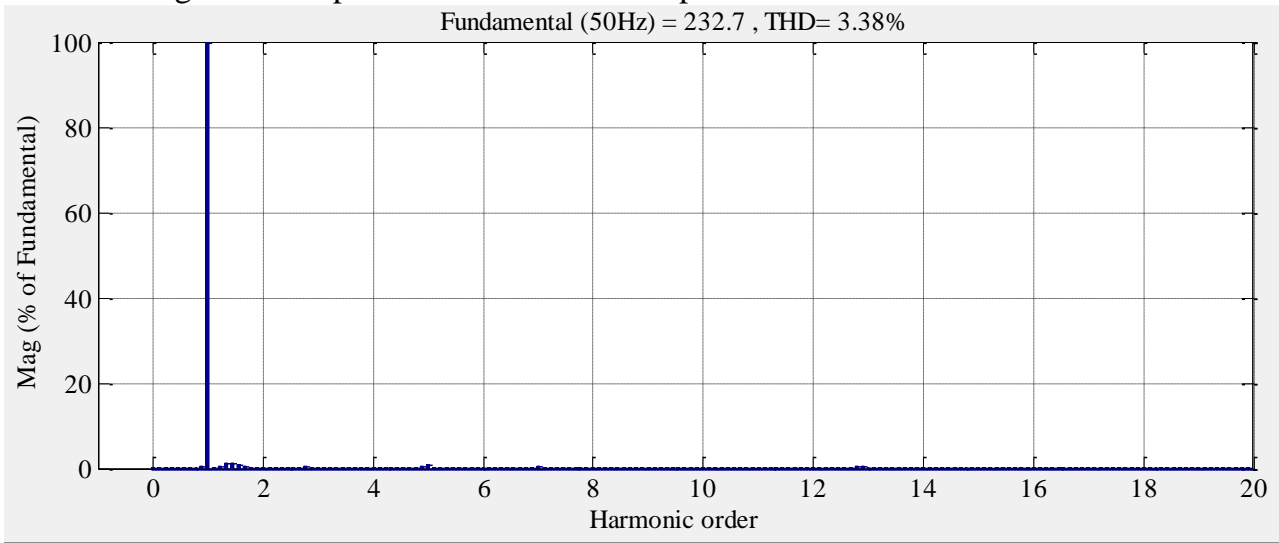

Figure 7: The supply current harmonic spectrum with the parameters in the stable domain.
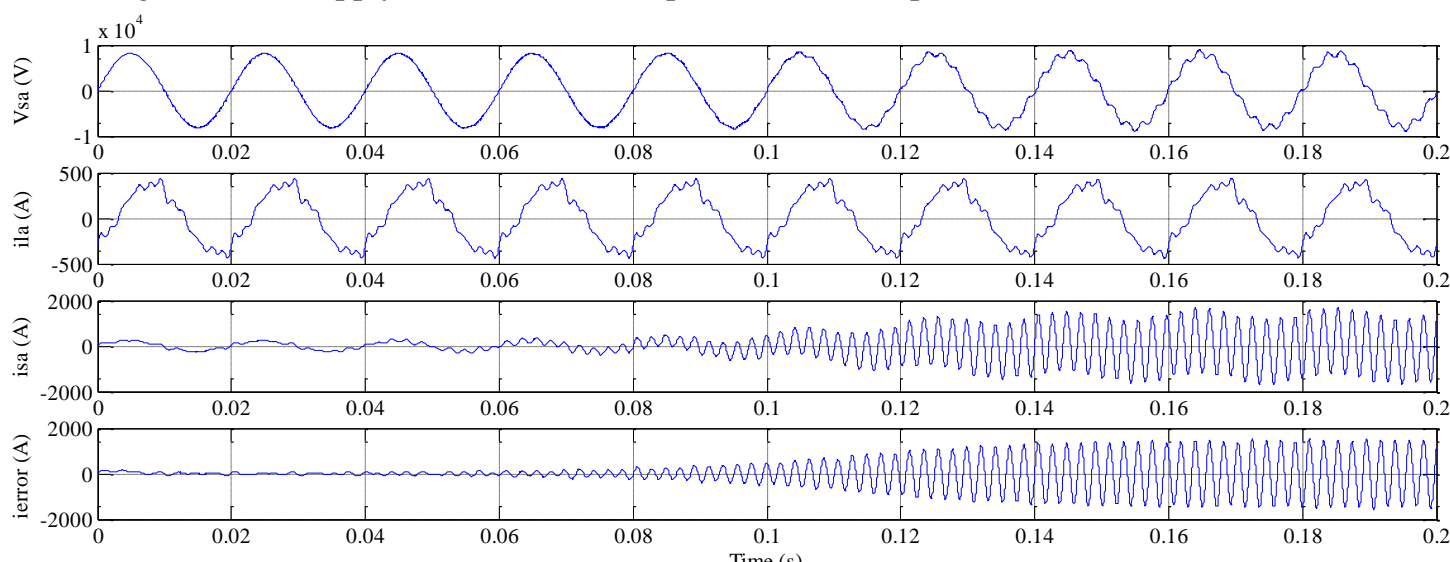

Figure 8: Response of HAPF with the parameters outside of stable domain. 


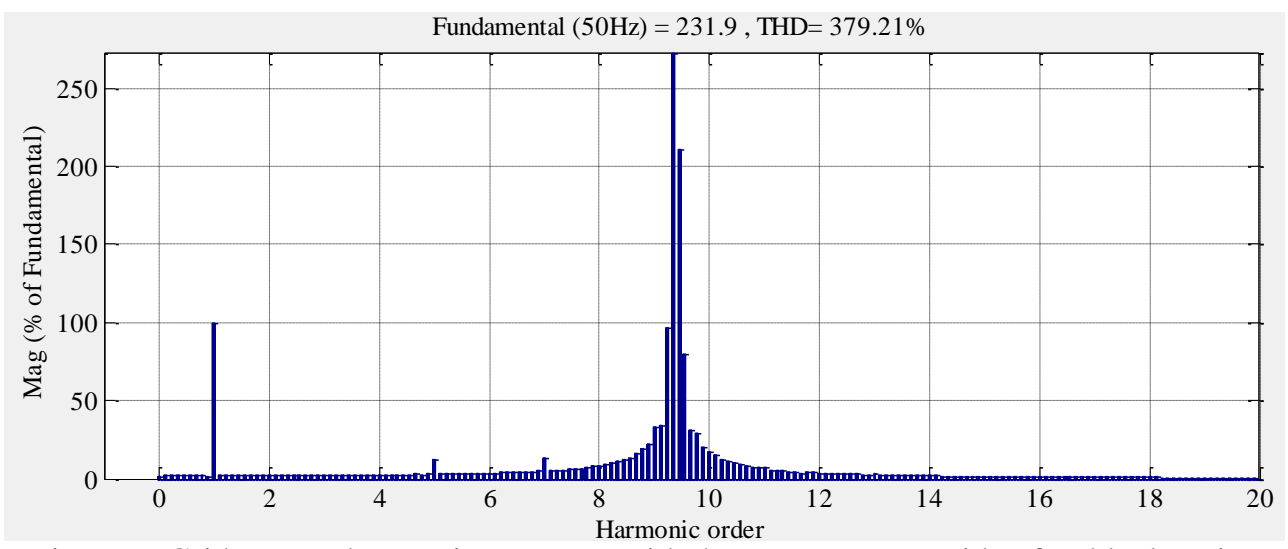

Figure 9: Grid current harmonic spectrum with the parameters outside of stable domain.

According to the obtained simulation results, in the case of parameters of HAPF outside of stable domains cannot be stabilized for the filtering as well as the power system network that the filtering is connected. In this case, the total harmonic distortion and individual harmonic will be raised much more than in the case of parameters in stable domain. Thus, with time delay highly increases will result in adverse impacts, loss of stability of HAPF. Power quality of the power system will become very poor and unachievable standards for connecting to the grid.

\section{CONCLUSION}

The paper has built the mathematical model of HAPF considering the time delay and analyzed the impact of the time delay on the stability of the system HAPF. When the time delay becomes smaller, the stability of HAPF is higher, and vice versa. The parameters of filtering outside of stable domain and longer time delay are unstable with HAPF system as well as power system that the filtering is connected. Thus power quality will not achieve international standards with requirements becoming more and more stringent. The results of this study can serve as a basis for choice parameters of HAPF in considering time delay, and also ensure stability and more efficient operation of HAPF system.

\section{APPENDIX}

$$
\begin{aligned}
c_{11}= & T_{i} \tau^{2} A_{1} ; c_{12}=T_{i}\left(2 A_{1}+2 \tau A_{2}+\tau^{2} A_{3}\right) c_{13}=T_{i}\left(2 A_{3}+2 \tau A_{4}+\tau^{2} A_{5}+2 n K_{c} C_{F} B_{1}\right) \\
c_{14}= & T_{i}\left(2 A_{5}+2 \tau A_{6}+\tau^{2} A_{7}+2 n K_{c} C_{F} B_{3}\right) ; c_{15}=T_{i}\left(2 A_{7}+2 \tau A_{8}+\tau^{2} A_{9}+2 n K_{c} C_{F} B_{5}\right) \\
c_{16}= & 2 T_{i}\left(A_{9}+\tau+\tau^{2}+n K_{c} C_{F} B_{7}\right) \\
c_{21}= & T_{i}\left(2 \tau A_{1}+\tau^{2} A_{2}\right) ; c_{22}=T_{i}\left(2 A_{2}+2 \tau A_{3}+\tau^{2} A_{4}\right) c_{23}=T_{i}\left(2 A_{4}+2 \tau A_{5}+\tau^{2} A_{6}+2 n K_{c} C_{F} B_{2}\right) \\
c_{24}= & T_{i}\left(2 A_{6}+2 \tau A_{7}+\tau^{2} A_{8}+2 n K_{c} C_{F} B_{4}\right) ; c_{25}=T_{i}\left(2 A_{8}+2 \tau A_{9}+\tau^{2}+2 n K_{c} C_{F} B_{6}\right) c_{26}=2 T_{i}\left(1+n K_{c} C_{F}\right) \\
c_{31}= & {\left[T_{i}\left(2 A_{1}+2 \tau A_{2}+\tau^{2} A_{3}\right)-\frac{T_{i} \tau^{2} A_{1}}{T_{i}\left(2 \tau A_{1}+\tau^{2} A_{2}\right)} T_{i}\left(2 A_{2}+2 \tau A_{3}+\tau^{2} A_{4}\right)\right] } \\
c_{32}= & T_{i}\left(2 A_{3}+2 \tau A_{4}+\tau^{2} A_{5}+2 n K_{c} C_{F} B_{1}\right)- \\
& -\frac{T_{i} \tau^{2} A_{1}}{T_{i}\left(2 \tau A_{1}+\tau^{2} A_{2}\right)} T_{i}\left(2 A_{4}+2 \tau A_{5}+\tau^{2} A_{6}+2 n K_{c} C_{F} B_{2}\right) \\
c_{33}= & T_{i}\left(2 A_{5}+2 \tau A_{6}+\tau^{2} A_{7}+2 n K_{c} C_{F} B_{3}\right)- \\
& -\frac{T_{i} \tau^{2} A_{1}}{T_{i}\left(2 \tau A_{1}+\tau^{2} A_{2}\right)} T_{i}\left(2 A_{6}+2 \tau A_{7}+\tau^{2} A_{8}+2 n K_{c} C_{F} B_{4}\right)
\end{aligned}
$$




$$
\begin{aligned}
& c_{34}=T_{i}\left(2 A_{7}+2 \tau A_{8}+\tau^{2} A_{9}+2 n K_{c} C_{F} B_{5}\right)- \\
& -\frac{T_{i} \tau^{2} A_{1}}{T_{i}\left(2 \tau A_{1}+\tau^{2} A_{2}\right)} T_{i}\left(2 A_{8}+2 \tau A_{9}+\tau^{2}+2 n K_{c} C_{F} B_{6}\right) \\
& c_{35}=2 T_{i}\left(A_{9}+\tau+\tau^{2}+n K_{c} C_{F} B_{7}\right)-\frac{T_{i} \tau^{2} A_{1}}{T_{i}\left(2 \tau A_{1}+\tau^{2} A_{2}\right)} 2 T_{i}\left(1+n K_{c} C_{F}\right) \\
& c_{41}=T_{i}\left(2 A_{2}+2 \tau A_{3}+\tau^{2} A_{4}\right)- \\
& -\frac{T_{i}\left(2 \tau A_{1}+\tau^{2} A_{2}\right)}{\left[T_{i}\left(2 A_{1}+2 \tau A_{2}+\tau^{2} A_{3}\right)-\frac{T_{i} \tau^{2} A_{1}}{T_{i}\left(2 \tau A_{1}+\tau^{2} A_{2}\right)} T_{i}\left(2 A_{2}+2 \tau A_{3}+\tau^{2} A_{4}\right)\right]} \times c_{32} \\
& c_{42}=T_{i}\left(2 A_{4}+2 \tau A_{5}+\tau^{2} A_{6}+2 n K_{c} C_{F} B_{2}\right)- \\
& -\frac{T_{i}\left(2 \tau A_{1}+\tau^{2} A_{2}\right)}{\left[T_{i}\left(2 A_{1}+2 \tau A_{2}+\tau^{2} A_{3}\right)-\frac{T_{i} \tau^{2} A_{1}}{T_{i}\left(2 \tau A_{1}+\tau^{2} A_{2}\right)} T_{i}\left(2 A_{2}+2 \tau A_{3}+\tau^{2} A_{4}\right)\right]} \times c_{33} \\
& c_{43}=T_{i}\left(2 A_{6}+2 \tau A_{7}+\tau^{2} A_{8}+2 n K_{c} C_{F} B_{4}\right)-\frac{T_{i}\left(2 \tau A_{1}+\tau^{2} A_{2}\right)}{c_{31}} c_{34} \\
& c_{44}=T_{i}\left(2 A_{8}+2 \tau A_{9}+\tau^{2}+2 n K_{c} C_{F} B_{6}\right)- \\
& -\frac{T_{i}\left(2 \tau A_{1}+\tau^{2} A_{2}\right)}{\left[T_{i}\left(2 A_{1}+2 \tau A_{2}+\tau^{2} A_{3}\right)-\frac{T_{i} \tau^{2} A_{1}}{T_{i}\left(2 \tau A_{1}+\tau^{2} A_{2}\right)} T_{i}\left(2 A_{2}+2 \tau A_{3}+\tau^{2} A_{4}\right)\right]} c_{35} \\
& c_{45}=2 T_{i}\left(1+n K_{c} C_{F}\right) \\
& c_{51}=T_{i}\left(2 A_{3}+2 \tau A_{4}+\tau^{2} A_{5}+2 n K_{c} C_{F} B_{1}\right)- \\
& -\frac{T_{i} \tau^{2} A_{1}}{T_{i}\left(2 \tau A_{1}+\tau^{2} A_{2}\right)} T_{i}\left(2 A_{4}+2 \tau A_{5}+\tau^{2} A_{6}+2 n K_{c} C_{F} B_{2}\right)-\frac{c_{31}}{c_{41}} c_{42} \\
& c_{52}=T_{i}\left(2 A_{5}+2 \tau A_{6}+\tau^{2} A_{7}+2 n K_{c} C_{F} B_{3}\right)- \\
& -\frac{T_{i} \tau^{2} A_{1}}{T_{i}\left(2 \tau A_{1}+\tau^{2} A_{2}\right)} T_{i}\left(2 A_{6}+2 \tau A_{7}+\tau^{2} A_{8}+2 n K_{c} C_{F} B_{4}\right)-\frac{c_{31}}{c_{41}} c_{43} \\
& c_{53}=T_{i}\left(2 A_{7}+2 \tau A_{8}+\tau^{2} A_{9}+2 n K_{c} C_{F} B_{5}\right)- \\
& -\frac{T_{i} \tau^{2} A_{1}}{T_{i}\left(2 \tau A_{1}+\tau^{2} A_{2}\right)} T_{i}\left(2 A_{8}+2 \tau A_{9}+\tau^{2}+2 n K_{c} C_{F} B_{6}\right)-\frac{c_{31}}{c_{41}} c_{44} \\
& c_{54}=2 T_{i}\left(A_{9}+\tau+\tau^{2}+n K_{c} C_{F} B_{7}\right)-\frac{T_{i} \tau^{2} A_{1}}{T_{i}\left(2 \tau A_{1}+\tau^{2} A_{2}\right)} 2 T_{i}\left(1+n K_{c} C_{F}\right)-\frac{c_{31}}{c_{41}} c_{45} \\
& c_{61}=c_{42}-\frac{c_{41}}{c_{51}} c_{52} ; c_{62}=c_{43}-\frac{c_{41}}{c_{51}} c_{53} ; c_{63}=c_{44}-\frac{c_{41}}{c_{51}} c_{54}, c_{64}=c_{45} ; c_{71}=c_{52}-\frac{c_{51}}{c_{61}} c_{62} ; c_{72}=c_{53}-\frac{c_{51}}{c_{61}} c_{63} ; \\
& c_{73}=c_{54}-\frac{c_{51}}{c_{61}} c_{64} ; c_{81}=c_{62}-\frac{c_{61}}{c_{71}} c_{72} ; c_{82}=c_{63}-\frac{c_{61}}{c_{71}} c_{73} ; c_{83}=c_{64} \\
& c_{91}=c_{72}-\frac{c_{71}}{c_{81}} c_{82} ; c_{92}=c_{73}-\frac{c_{71}}{c_{81}} c_{83} ; c_{101}=c_{82}-\frac{c_{81}}{c_{91}} c_{92} ; c_{102}=c_{83} ; c_{111}=c_{92}-\frac{c_{91}}{c_{101}} c_{102} ; c_{121}=c_{102}
\end{aligned}
$$

The expressions from A1 to A9 and B1 to B7 are expressed: 


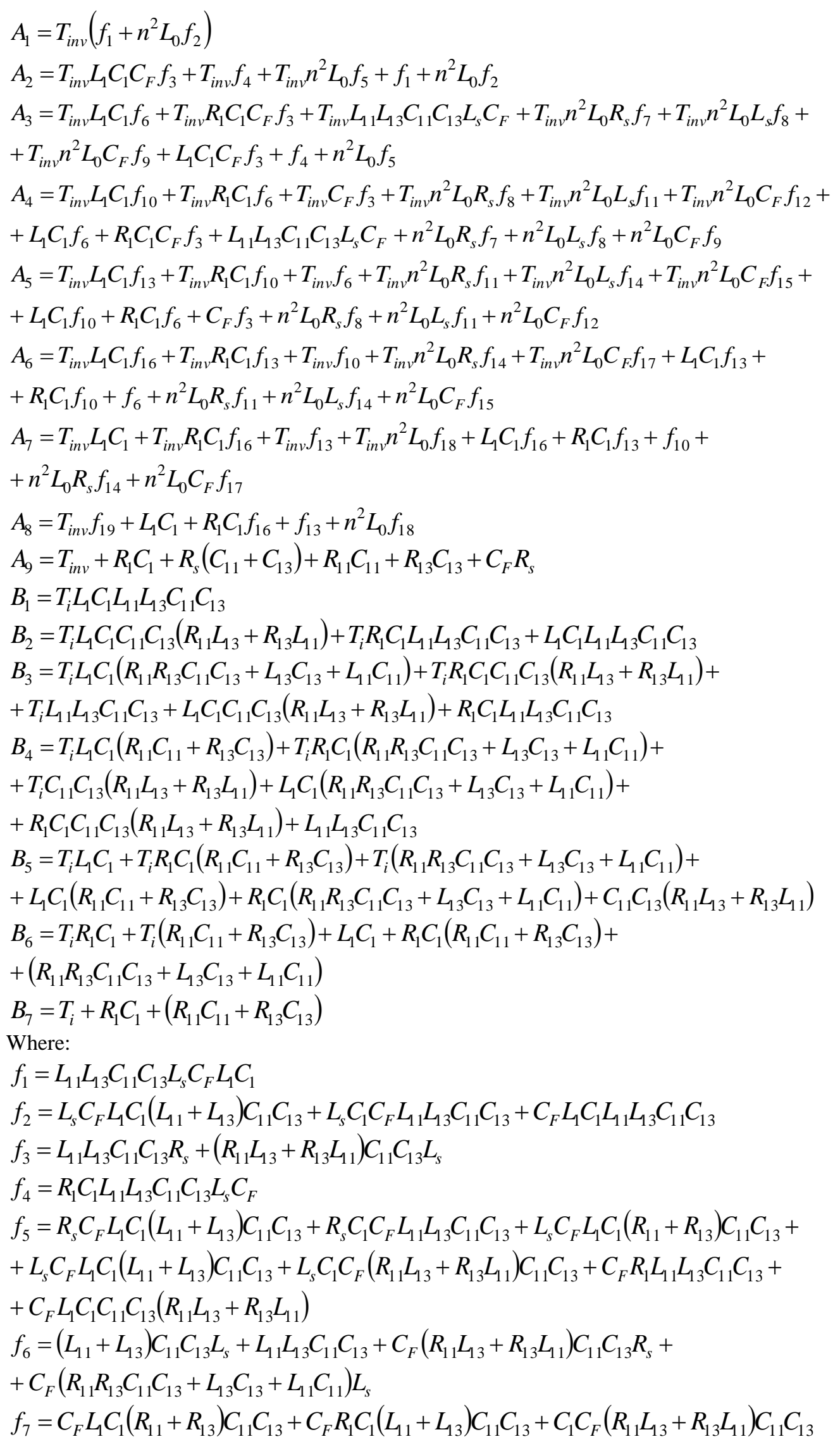




$$
\begin{aligned}
& f_{8}=C_{F} L_{1} C_{1}\left(C_{11}+C_{13}\right)+C_{F} R_{1} C_{1}\left(R_{11}+R_{13}\right) C_{11} C_{13}+\left(C_{F}+C_{1}\right)\left(L_{11}+L_{13}\right) C_{11} C_{13}+ \\
& C_{1} C_{F}\left(R_{11} R_{13} C_{11} C_{13}+L_{13} C_{13}+L_{11} C_{11}\right) \\
& f_{9}=L_{11} L_{13} C_{11} C_{13}\left(1+\frac{C_{1}}{C_{F}}\right)+C_{11} C_{13}\left(R_{11} L_{13}+R_{13} L_{11}\right) R_{1} C_{1}+ \\
& +\left(R_{11} R_{13} C_{11} C_{13}+L_{13} C_{13}+L_{11} C_{11}\right) L_{1} C_{1} \\
& f_{10}=\left(L_{11}+L_{13}\right) C_{11} C_{13} R_{s}+L_{s}\left(R_{11}+R_{13}\right) C_{11} C_{13}+\left(R_{11} L_{13}+R_{13} L_{11}\right) C_{11} C_{13}+ \\
& +C_{F}\left(R_{11} R_{13} C_{11} C_{13}+L_{13} C_{13}+L_{11} C_{11}\right) R_{s}+C_{F}\left(R_{11} C_{11}+R_{13} C_{13}\right) L_{s} \\
& f_{11}=C_{F} R_{1} C_{1}\left(C_{11}+C_{13}\right)+\left(C_{F}+C_{1}\right)\left(R_{11}+R_{13}\right) C_{11} C_{13}+C_{1} C_{F}\left(R_{11} C_{11}+R_{13} C_{13}\right) \\
& f_{12}=C_{11} C_{13}\left(R_{11} L_{13}+R_{13} L_{11}\right)\left(1+\frac{C_{1}}{C_{F}}\right)+\left(R_{11} R_{13} C_{11} C_{13}+L_{13} C_{13}+L_{11} C_{11}\right) R_{1} C_{1}+ \\
& +\left(R_{11} C_{11}+R_{13} C_{13}\right) L_{1} C_{1} \\
& f_{13}=R_{s}\left(R_{11}+R_{13}\right) C_{11} C_{13}+L_{s}\left(C_{11}+C_{13}\right)+R_{11} R_{13} C_{11} C_{13}+L_{13} C_{13}+L_{11} C_{11}+ \\
& +C_{F}\left(R_{11} C_{11}+R_{13} C_{13}\right) R_{s}+C_{F} L_{s} \\
& f_{14}=\left(C_{F}+C_{1}\right)\left(C_{11}+C_{13}\right)+C_{1} C_{F} \\
& f_{15}=\left(R_{11} R_{13} C_{11} C_{13}+L_{13} C_{13}+L_{11} C_{11}\right)\left(1+\frac{C_{1}}{C_{F}}\right)+\left(R_{11} C_{11}+R_{13} C_{13}\right) R_{1} C_{1}+L_{1} C_{1} \\
& f_{16}=R_{s}\left(L_{13}+C_{13}\right)+R_{11} C_{11}+R_{13} C_{13}+C_{F} R_{s} \\
& f_{17}=\left(R_{11} C_{11}+R_{13} C_{13}\right)\left(1+\frac{C_{1}}{C_{F}}\right)+R_{1} C_{1} \\
& f_{18}=C_{F}\left(1+\frac{C_{1}}{C_{F}}\right) \\
& f_{19}=R_{1} C_{1}+R_{s}\left(C_{11}+C_{13}\right)+R_{11} C_{11}+R_{13} C_{13}+C_{F} R_{s} \\
& \left.f_{F}\right)
\end{aligned}
$$

\section{REFERENCES}

[1] Haihong Huang, Huan Xue, Xin Liu, Haixin Wang, The study of Active Power Filter using a universal harmonic detection method. IEEE ECCE Asia Downunder (ECCE Asia), 2013, pp. 591 - 595.

[2] Panigrahi R, Subudhi B, Panda P C, Model predictive-based shunt active power filter with a new reference current estimation strategy, IET Power Electronics, vol. 8, no. 2, pp. 221 - 233, 2015.

[3] Panda G, Dash S K, Sahoo N, Comparative performance analysis of Shunt Active power filter and Hybrid Active Power Filter using FPGA-based hysteresis current controller, IEEE 5th India International Conference on Power Electronics (IICPE), 2012, pp. 1-6.

[4] Suresh Y, Panda A K, Suresh M, Real-time implementation of adaptive fuzzy hysteresis-band current control technique for shunt active power filter, IET Power Electronics, vol. 5, no. 7, pp. 1188-1195, 2012.

[5] An Luo, Zhikang Shuai, Wenji Zhu, Ruixiang Fan, Chunming Tu, Development of Hybrid Active Power Filter Based on the Adaptive Fuzzy Dividing Frequency-Control Method, IEEE transactions on power delivery, vol. 24, no. 1, pp. 424-432, 2009. 
[6] Chen Wei, LI Qin, Lu Tingjin, Rong Penghui, Zhao Yanqing, Method of Event Detection Based on Dynamic Hybrid Fuzzy Logic System, International Conference on Intelligent Computation Technology and Automation, 2010, pp. 661-663.

[7] Demirdelen T, Inci M, Bayindir K C, Tumay M, Review of Hybrid Active Power Filter Topologies and Controllers, $4^{\text {th }}$ international conference on Power Engineering, Energy and Electrical Drives, 2013, pp. 587 - 592.

[8] Ertay M M, Tosun S, Zengin A, Simulated annealing based passive power filter design for a medium voltage power system, International Symposium on Innovations in Intelligent Systems and Applications, 2012, pp. 1-5.

[9] Herman L, Papic I, Blazic B, A Proportional-Resonant Current Controller for Selective Harmonic Compensation in a Hybrid Active Power Filter, IEEE transactions on power delivery, vol. 29, no. 5, pp. 2055 - 2065, 2014.

[10] Liu Wei, Zhang Dawei, Study on a series hybrid active power filter based on novel fuzzy immune PID controller, International Conference on Measurement, Information and Control, 2012, pp. 520-523.

[11] M Chau, A Luo, F Ma, Z Shuai, T Nguyen, W Wang, Online control method with time-delay compensation for hybrid active power filter with Injection Circuit, IET Power Electronics, vol. 5, no. 8, pp. 1472-1482, 2012.

[12] Mahajan V, Agarwal P, Gupta H.O, Simulation of shunt active power filter using instantaneous power theory. $5^{\text {th }}$ IEEE Power India Conference, 2012, pp.1-5.

[13] MinhThuyen Chau, An Luo, VanBao Chau, PID-Fuzzy Control Method with Time Delay Compensation for Hybrid Active Power Filter with Injection Circuit, International Journal of Computer Applications, vol. 36,no. 8, pp. 15-21, 2011.

[14] Nien-Che Yang, Minh-Duy Le, Multi-objective bat algorithm with time-varying inertia weights for optimal design of passive power filters set, IET Generation, Transmission \& Distribution, vol. 9, no. 7, pp. $644-654,2015$. [15] Tzung-Lin Lee, Yen-Ching Wang, Jian-Cheng Li, Guerrero, J M, Hybrid Active Filter With Variable Conductance for Harmonic Resonance Suppression in Industrial Power Systems. IEEE Transactions on Power Electronics, vol 62, no. 2, pp. 746 - 756, 2015.

[16] Wai-Hei Choi, Chi-Seng Lam, Man-Chung Wong; Ying-Duo Han, Analysis of DC-Link Voltage Controls in Three-Phase Four-Wire Hybrid Active Power Filters, IEEE Transactions on Power Electronics, vol. 28, no. 5, pp. $2180-2191,2013$.

[17] IEEE Application Guide for IEEE Std 1547M. 2009. IEEE Standard for Interconnecting Distributed Resources with Electric Power Systems.

[18] IEEE Std 519-2014. IEEE Recommended Practice and Requirements for Harmonic Control in Electric Power Systems. 


\section{PHÂN TÍCH ẢNH HƯởNG CỦA THỜI GIAN TRẼ ĐẾN SỬ ỔN ĐỊNH CỦA MẠCH LỌC TÍCH CỰC DẠNG LAI GHÉP}

Tóm tắt. Mạch lọc tích cực dạng lai ghép (HAPF) có hiệu quả cao trong việc cải thiện chất lượng điện năng trên hệ thống điện. Trong bài báo này, một phân tích ổn định của HAPF có xét đến thời gian trễ đã được thực hiện. Mô hình toán của HAPF với thời gian trễ đã được thành lập. Trên cơ sở đó, miền ổn định của các thông số HAPF đã được xác định dựa vào tiêu chuẩn ổn định Routh. Các kết quả mô phỏng dựa vào phần mềm Matlab đã chứng tỏ được rằng: thời gian trễ có ảnh hưởng rõ nét đến tính năng ổn định của hệ thống HAPF. Nghiên cứu này có ý nghĩa thực tế trong thiết kế và điều khiển của HAPF trong thời gian thực.

Từ khóa: Mạch lọc thụ động, mạch lọc tích cực dạng lai ghép, phân tích ổn định, thời gian trễ.

Ngày nhận bài: 31/12/2017

Ngày chấp nhận đăng: 07/11/2018 